\title{
ERRATUM
}

\section{CHROMATIN AND CD4, CD8A and CD8B GENE EXPRESSION DURING THYMIC DIFFERENTIATION}

Dimitris Kioussis and Wilfried Ellmeier

Nature Reviews Immunology 2, 909-919 (2002)

Three figures in this article are labelled incorrectly.

- In Figure 3b, page 913, the second and third transgenic constructs should have the following activity patterns in the thymus: for the second construct, DN + DP + CD4 + CD8 + ; for the third construct, DN - DP - CD4 + CD8 +.

- In Figure 4a, page 915, the labels for $C d 8 a$ and $C D 8 b$ should be reversed, such that $C d 8 b$ lies upstream of $C d 8 a$.

- In Figure 5, page 917, the second chromatin structure should be labelled as $\mathrm{CD} 4^{-} \mathrm{CD} 8^{+}$ISP, not as $\mathrm{CD}^{-} \mathrm{CD}^{-}$ISP. 